\title{
Gender Difference in the Expectation and Receipt of Filial Piety Among U.S Chinese Older Adults
}

\author{
Xinqi Dong, M.D. MPH (Corresponding author) \\ Rush Institute for Healthy Aging, Rush University Medical Center, \\ 1645 West Jackson, Suite 675, Chicago, IL, USA \\ Tel: 1-312-942-3350 E-mail: xinqi_dong@rush.edu \\ Manrui Zhang, MPH, MSW \\ Rush Institute for Healthy Aging, Rush University Medical Center, \\ 1645 West Jackson, Suite 675, Chicago, IL, USA \\ Tel: 1-314-570-6906_E-mail: manrui_zhang@rush.edu
}

Received: April 17, 2015 Accepted: June 10, 2015 Published: June 16, 2015

doi:10.5296/jsss.v2i2.7827 URL: http://dx.doi.org/10.5296/jsss.v2i2.7827

\begin{abstract}
Background: Filial piety is a fundamental virtue that defines children's care-giving obligation to older parents in Chinese families. This study aims to evaluate whether gender difference exists in the expectation and receipt of filial piety among U.S Chinese older adults. Methods: Data were drawn from the PINE study, a population-based study of U.S. Chinese older adults aged 60 and above in the greater Chicago area. Guided by a community-based participatory research approach, a total of 3,159 Chinese older adults aged 60 and above were surveyed. Filial piety was examined in six domains, including care, respect, greeting, happiness, obedience, and financial support. Socio-demographic correlates with expectations and receipt of filial piety were examined. Multivariate regression analyses were conducted. Results: Female older adults were 1.02 points higher than male older adults in their perceived receipt of filial piety $(\mathrm{PE}=1.02, \mathrm{p}<0.001)$ adjusted for the socio-demographics. Older women received more respect $(p<0.001)$, greetings $(p<0.001)$, happiness $(p<0.01)$, and obedience $(\mathrm{p}<0.05)$. Women with an older age $(\mathrm{r}=0.06, \mathrm{p}<0.05)$ and a lower educational level $(\mathrm{r}=-0.11, \mathrm{p}<0.01)$ received more filial piety while similar trends were not discovered among men. Being married was correlated with a higher level of filial piety receipt among
\end{abstract}


men $(r=0.07 . p<0.05)$ while the correlation was not significant among women.

Discussion: This study provides insights to understand how the gender of the older parents influences their expectation and receipt of filial piety. Our findings have important implications to guide elder care practices with cultural and gender sensitivity.

Keywords: Population studies, Gender difference, Older adults, Filial piety, Chinese 


\section{Introduction}

Filial piety (孝 xiào) has important implications for parent-child relationships and family care-giving practices in Chinese families (Zhan \& Montgomery, 2003). As an essential component of Confucianism, filial piety defines the children's role to provide adequate emotional and financial care and support for their older parents, reciprocating for the care they received as children (Dai \& Dimond, 1998; Smith \& Hung, 2012). Throughout Chinese history, the belief and practice of filial piety have influenced the health and social well-being of Chinese older adults. Filial piety serves as protective factor against stressors and indicates better social support and connects between family members ( $\mathrm{Li}$ et al., 2011; $\mathrm{Ng} \&$ Bhugra, 2008). Statistics also indicate that older adults who perceive their children as filial have decreased their use of health services (Li \& Chi, 2011).

The gender of older parents and adult children may influence the belief and practices of filial piety in Chinese cultural context. In China, women are traditionally viewed as obligatory caregivers, providing care in the daily lives for their children and husbands (Short, Fengying, Siyuan, \& Mingliang, 2001). On the other hand, men are culturally identified as the authority figures in the family and expected to be role models and mentors for their children (Short et al., 2001). Due to those gender-based stereotypes, it is very likely that Chinese female and male parents interact with their children differently, and thus, young children are raised to recognize that they obtained different forms of support from their mothers and fathers. When parents get old, although the family dynamic and care-giving responsibilities may have changed substantively, those gender-based patterns of interaction formulated over years are likely to sustain in lifetime and influence parent-child relationships. Given that filial piety is a reciprocal behavior built upon the relationships between parents and children, female and male older adults may experience filial piety expectation and receipt very differently. While a great number of literatures in filial piety emphasized the gender differences among adult children in practicing filial piety (Brakman, 1994; Chao \& Roth, 2000; Chappell \& Kusch, 2007), the gender difference in the expectation and receipt of filial piety among older adults remains unclear. One study in Beijing indicates that no gender difference was observed in older adults' expectation of filial piety (Yue \& Ng, 1999). In comparison, some other studies point out women are stronger in enforcing filial values than men (Ho, 1994; Ho, 1996; Seelbach, 1977).

The gender disparities in the belief and practice of filial piety evolve with social and economic progress and policy change in China. In the middle $20^{\text {th }}$ century, Mao Zedong, the communist leader who is recognized as the founding father of the People's Republic of China, created policies to promote gender equality within the Chinese family, weakening the hierarchical position of the father as the head of household for subsequent generations (Zhan \& Montgomery, 2003). Moreover, the economic reform in the 1970s privatized many state-own businesses and abandoned the idea of communal egalitarianism and job security, which were promised in communist social contracts. Older adults and women, who were often unable to keep pace with the advancement of knowledge and skills during transformation, were at particular risk of losing their jobs and social benefits in the free market competitions, indicating greater needs in obtaining filial care from children (Tang \& 
Parish, 2000; Zhan \& Montgomery, 2003). Moreover, the one-child policy implemented in the late 1980s has fundamentally changed the structure and size of Chinese families, which led to change on women's obligations as the family caregivers (Short et al., 2001). For overseas Chinese communities, the gender differences in filial piety beliefs and practices are furthermore effected by the experience of immigration, the subsequent degree of acculturation, language ability and proficiency, etc (Ng, Phillips, \& Lee, 2002; Seelbach, 1977).

Chinese community represents one of the most fast-growing racial groups in the U.S with a population of approximately four million. Compared to other ethnic groups, the Chinese community is relatively older with $15.4 \%$ aged 65 and over (Bureau., 2010). Nearly three in four of Chinese older adults in the U.S were not native-born and one third of them immigrated to U.S after they reached the age of 60 . Therefore, Chinese older adults may have a stronger attachment to Chinese family-oriented values and the traditional conceptualization of intergenerational relationships (Kuo \& Roysircar, 2004; Mui \& Shibusawa, 2008). However, women's familial obligation may be altered due to their exposure to American lifestyle and culture: women's traditional role, as obedient and dependent caregivers, could become less relevant when confronted with western feminist beliefs, possibly freeing women from burdensome family obligations (Chow, 1987). While a previous study suggested that filial behaviors are still commonly expected and practiced among the Chinese community in Chicago area (Dong, Zhang, \& Simon, 2014a), little attention was paid to investigate gender differences in perceived filial care among U.S. Chinese older adults. A better understanding of whether difference exhibited in the expectation and receipt of filial piety between older men and women may have important implications in planning and organizing family care for older adults with cultural and gender sensitivity in mind.

Considering the above-mentioned cultural norms and the changes of social policy over years in China, we postulate there is a gender difference in the expectation and receipt of filial piety among the Chinese older adults in the U.S. In order to test our hypotheses, this study aims to 1) identify the endorsement and levels of the expectation and receipt of filial piety by gender; 2) identify the correlations between the expectation and receipt of filial piety, socio-demographics, and self reported health measures among female and male cohorts; and 3) conduct regression analyses to detect gender difference in filial piety controlling for socio-demographics in a community-dwelling Chinese aging population in U.S.

\section{Methods}

\subsection{Population and Settings}

The Population Study of Chinese Elderly in Chicago (PINE) is a population-based epidemiological study of U.S. Chinese older adults aged 60 and over in the greater Chicago area. Briefly, the purpose of the PINE study is to collect community-level data of U.S. Chinese older adults to examine the key cultural determinants of health and well-being. The project was initiated by a synergistic community-academic collaboration between Rush Institute for Healthy Aging, Northwestern University, and many community-based social 
services agencies and organizations throughout the greater Chicago area (Dong, Wong, \& Simon, 2014).

In order to ensure study relevance to the well-being of the Chinese community and enhance community participation, the PINE study implemented extensive culturally and linguistically appropriate recruitment strategies strictly guided by community-based participatory research (CBPR) approach (Dong, Chang, Wong, \& Simon, 2011). Over twenty social services agencies, community centers, health advocacy agencies, faith-based organizations, senior apartments and social clubs served as the basis of study recruitment sites. Eligible participants were approached through routine social services and outreach efforts serving Chinese American families in the Chicago city and suburban areas. Out of 3,542 eligible participants, 3,159 agreed to participate in the study, yielding a response rate of $91.9 \%$.

Based on the available census data drawn from U.S Census 2010 and a random block census project conducted in the Chinese community in Chicago, the PINE study is representative of the Chinese aging population in the greater Chicago area with respective to key demographic attributes including age, sex, income, education, number of children, and country of origin (Simon, Chang, Rajan, Welch, \& Dong, 2014). The study was approved by the institutional review board of the Rush University Medical Center.

\subsection{Measurements}

\subsubsection{Socio-demographics}

Basic demographic information was collected including age (yrs), sex, education level, annual income, marital status (married/separated/divorced/widowed), number of children, living arrangement, and years in the U.S. Education was assessed by asking participants the years of highest educational level completed, ranging from 0 to 17 years or more. Living arrangement was assessed by asking participants how many people live in their household besides themselves and was categorized into three groups: (1) living alone; (2) living with 1-2 persons; (3) living with 2-3 persons; (4) living with 4 or more persons. Income groups were divided into four groups: (1)\$0-\$4,999 per year; (2) $\$ 5,000-\$ 9,999$ per year; (3) $\$ 10,000-14,999$ per year; (4) more than $\$ 15,000$ per year. Language was assessed by ability to speak and preference of English, Cantonese, Mandarin, or Toisanese. We created a dichotomous country of origin variable by categorizing respondents into the "China" group if they were born in mainland China and "other" group for other countries and regions.

\subsubsection{Overall Health Status, Quality of Life, and Health Changes over Last Year}

Overall health status was measured by "In general, how would you rate your health" on a four point scale (1=poor, 2=fair, 3=good, 4=very good). Quality of life was assessed by asking "in general, how would you rate your quality of life" on a four point scale ranging from ( 1 =poor, 2 =fair, 3 =good, $4=$ =very good). Health changes in last year were measured by "compared to one year ago, how would you rate your health now?" on a five point scale ( $1=$ much worse; $2=$ somewhat worse; $3=$ about the same; $4=$ somewhat better; $5=$ much better than one year ago) and were categorized into three groups: (1) improved health; (2) same health; (3) worsened health. 


\subsubsection{Filial Piety}

Filial piety was assessed in six domains, including respect, happiness, care, greetings, obedience, and financial support, based on the conceptual model proposed by Gallois and colleagues (Gallois et al., 1996). On a five-point-scale ( 1 =very little; $2=$ rather little; $3=$ average; $4=$ rather a lot; $5=$ very much), participants were asked how much care, respect, happiness, obedience, financial support, and how many greetings they expected from their children. Similarly, participants were then asked to evaluate their actual receipt of care, respect, greetings, happiness, obedience, and financial support ( 1 =very little; $5=$ very much). Participants were categorized into "lower than average" group if they expected or received "very little" or "rather little" amount of filial care. If they perceived their expectation or receipt of filial care as "rather a lot" or "very much", they were at the "higher than average" group. Otherwise, participants were in the "average" group, indicating that their expectation or receipt of filial piety is in the middle of "rather little" and "rather a lot". Internal consistency reliability was 0.88 for the filial piety assessment in our study sample (Dong, Zhang, \& Simon, 2014a).

\subsection{Data Analysis}

Descriptive statistics were used to summarize the endorsement of filial piety expectation and receipt among a male cohort and a female cohort. The Chi-square tests were used to examine whether the distribution of filial piety endorsements differed significantly by gender. Means, standard deviations, and ANOVA F-test were used to describe the gender differences of the filial piety expectation and filial piety receipt. The Pearson Correlation coefficients were used to examine the correlations between socio-demographic variables and filial piety expectation and receipt among the men cohort and women cohort. Multivariate regression analyses were conducted in order to detect gender difference in the expectation and receipt of filial piety after controlling for socio-demographics. Statistical analyses were conducted using SAS, Version 9.2 (SAS Institute Inc., Cary, NC).

\section{Results}

\subsection{Sample Characteristics}

Of the 3,159 participants who were enrolled in study, 58.9\% were female. The average age of men and women was $72.2(\mathrm{SD}=7.9)$ and $72.9(\mathrm{SD}=8.6)$, respectively. The majority of participants had less than high school education (78.9\%) and an annual income less than $\$ 10,000(85.1 \%)$. The majority of participants $(71.3 \%)$ were married. Statistical differences were significant between female and male participants in regard to education, income, marital status, number of children, number of grandchildren, and living arrangement. Compared with female participants in our study, a larger proportion in our male cohort had an education level of 7 years or more, had an annual income lower than $\$ 5,000$, married, and lived with one person or more. 
3.2 Endorsement of Filial piety Expectation and Receipt by Gender

Table 1. Filial piety endorsement among women and men

Expectation of Filial Piety N(\%)

\begin{tabular}{|c|c|c|c|c|c|c|c|c|c|}
\hline & \multicolumn{3}{|c|}{ Lower than Average } & \multicolumn{3}{|l|}{ Average } & \multicolumn{3}{|c|}{ Higher than Average } \\
\hline & Women & Men & $\chi^{2}, \mathrm{p}$ & Women & Men & $\chi^{2}, \mathrm{p}$ & Women & Men & $\chi^{2}, \mathrm{p}$ \\
\hline \multirow{2}{*}{ Care } & 477 & 382 & & 371 & 293 & & 949 & 623 & \\
\hline & 26.5 & 29.4 & $10.5^{+}$ & 20.7 & 22.6 & $9.2^{\#}$ & 52.8 & 47.9 & $67.6^{+}$ \\
\hline \multirow{2}{*}{ Respect } & 166 & 151 & & 313 & 269 & & 1317 & 880 & \\
\hline & 9.3 & 11.6 & 0.7 & 17.4 & 20.6 & 3.3 & 73.3 & 67.8 & $86.9^{+}$ \\
\hline \multirow{2}{*}{ Greet } & 233 & 215 & & 386 & 305 & & 1176 & 780 & \\
\hline & 12.9 & 16.6 & 0.7 & 21.5 & 23.3 & $9.5^{\#}$ & 65.6 & 60.1 & $80.2^{+}$ \\
\hline \multirow{2}{*}{ Happiness } & 229 & 218 & & 430 & 342 & & 1136 & 741 & \\
\hline & 12.7 & 16.8 & 0.3 & -24 & 26.1 & $10.0^{\#}$ & 63.3 & 57.1 & $83.1^{+}$ \\
\hline \multirow{2}{*}{ Obey } & 329 & 272 & & 430 & 326 & & 1035 & 703 & \\
\hline & 18.4 & 21 & $5.4^{*}$ & 24 & 25.1 & $14.3^{+}$ & 57.6 & 54.0 & $63.4^{+}$ \\
\hline \multirow{2}{*}{ Financial } & 992 & 775 & & 527 & 344 & & 275 & 182 & \\
\hline & 55.3 & 59.6 & $26.6^{+}$ & 29.4 & 26.4 & $38.4^{+}$ & 15.3 & 14.0 & $18.9^{+}$ \\
\hline \multicolumn{10}{|c|}{ Receipt of Filial Piety N(\%) } \\
\hline \multirow{2}{*}{ Care } & 241 & 235 & & 464 & 356 & & 1093 & 708 & \\
\hline & 13.4 & 18.1 & 0.08 & 25.8 & 27.4 & $14.2^{+}$ & 60.8 & 54.5 & $82.3^{+}$ \\
\hline \multirow{2}{*}{ Respect } & 61 & 65 & & 308 & 270 & & 1429 & 966 & \\
\hline & 3.4 & 5.0 & 0.1 & 17.1 & 20.6 & 2.5 & 79.5 & 74.4 & $89.5^{+}$ \\
\hline \multirow{2}{*}{ Greeting } & 117 & 138 & & 346 & 312 & & 1334 & 850 & \\
\hline & 6.5 & 10.5 & 1.7 & 19.3 & 24 & 1.8 & 74.2 & 65.5 & $107.3^{+}$ \\
\hline \multirow{2}{*}{ Happiness } & 143 & 151 & & 450 & 400 & & 1203 & 750 & \\
\hline & 8.1 & 11.6 & 0.2 & 25 & 30.6 & 2.9 & 66.9 & 57.8 & $105.1^{+}$ \\
\hline \multirow{2}{*}{ Obey } & 180 & 161 & & 501 & 399 & & 1115 & 741 & \\
\hline & 10 & 12.3 & 1.1 & 27.9 & 30.7 & $11.6^{+}$ & 62.1 & 57.1 & $75.4^{+}$ \\
\hline \multirow{2}{*}{ Financial } & 639 & 537 & & 624 & 429 & & 533 & 333 & \\
\hline & 35.6 & 41.3 & $8.8^{*}$ & 34.7 & 33 & $36.1^{+}$ & 30 & 25.7 & $46.2^{+}$ \\
\hline
\end{tabular}

$* \mathrm{p}<0.05, \# \mathrm{p}<0.01,+\mathrm{p}<0.001$.

The distribution of women and men in the expectation and receipt of filial piety is shown in the Table 1. Except for financial care, more than $50 \%$ of both men and women endorsed that they expected and received the filial piety items on a higher than an average level. A larger proportion of women compared to men expected a higher than average level of respect $(73.3 \%$ vs. $67.8 \%, \mathrm{p}<0.001)$, greetings $(65.6 \%$ vs. $60.1 \%, \mathrm{p}<0.001)$, happiness $(63.3 \%$ vs. $57.1 \%, \mathrm{p}<0.001)$, obedience $(57.6 \%$ vs. $54.0 \%, \mathrm{p}<0.001)$, and care $(52.8 \%$ vs. $47.9 \%$, $\mathrm{p}<0.001)$. Financial support was the least expected filial care item; only $15.3 \%$ of men and $14.0 \%$ of women expected on a higher than average level $(\mathrm{p}<0.001)$. 
With regards to the receipt of filial piety, a larger proportion of women than men received a higher than average level of respect $(79.5 \%$ vs. $74.4 \%, \mathrm{p}<0.001)$, greetings $(74.2 \%$ vs. $65.5 \%$, $\mathrm{p}<0.001)$, happiness $(66.9 \%$ vs. $57.8 \% \mathrm{p}<0.001)$, obedience $(62.1 \%$ vs. $57.1 \% \mathrm{p}<0.001)$, care (60.8\% vs. $54.5 \%, \mathrm{p}<0.001)$, and financial support $(30.0 \%$ vs. $25.7 \%, \mathrm{p}<0.001)$.

\subsection{Mean of Filial Piety Expectation and Receipt}

On a scale of 5 to 30 , the receipt of filial care was higher among women $(\mathrm{M}=22.6, \mathrm{SD}=4.8)$ compared with men $(\mathrm{M}=21.6, \mathrm{SD}=5.2, \mathrm{p}<0.001)$. However, gender difference was not significant with regard to the expectations of filial piety (Table 2).

Table 2. Gender difference in mean of filial piety

\begin{tabular}{lllllll}
\hline & \multicolumn{3}{c}{ Expectation of Filial Piety } & \multicolumn{3}{c}{ Receipt of Filial Piety } \\
\hline \multirow{2}{*}{ Total } & Women & Men & F, p & Women & Men & $\mathrm{F}, \mathrm{p}$ \\
Care & $21.1(6.1)$ & $20.2(6.0)$ & 1.03 & $22.6(4.8)$ & $21.6(5.2)$ & $1.17^{+}$ \\
Respect & $3.4(1.4)$ & $3.3(1.4)$ & 1.01 & $3.8(1.2)$ & $3.6(1.2)$ & 1.03 \\
Greeting & $4.1(1.2)$ & $3.9(1.0)$ & 1.06 & $4.2(0.9)$ & $4.1(1.0)$ & $1.18^{+}$ \\
Happiness & $3.9(1.2)$ & $3.7(1.3)$ & 1.05 & $4.1(1.0)$ & $3.9(1.1)$ & $1.18^{+}$ \\
Obey & $3.8(1.2)$ & $3.6(1.2)$ & 1.04 & $3.9(1.0)$ & $3.7(1.1)$ & $1.15^{\#}$ \\
Financial & $3.6(1.3)$ & $3.5(1.3)$ & 1.00 & $3.8(1.0)$ & $3.7(1.1)$ & $1.11^{*}$ \\
\hline
\end{tabular}

$* \mathrm{p}<0.05, \# \mathrm{p}<0.01,+\mathrm{p}<0.001$.

With respect to each of the six filial care items, respect was placed with highest expectation and receipt among both women and men cohorts with mean scores ranging from 3.9 to 4.2 on a scale of 1-5. Financial support was the least expected and receipted filial care item with the mean scores ranging from 2.2 to 2.8 . Gender differences were observed with regards to the receipt of respect, greetings, happiness, and obedience. Women reported a higher level of receipt in regard to respect ( 4.2 vs. $4.1, \mathrm{p}<0.001$ ), greetings ( 4.1 vs $3.9, \mathrm{p}<0.001$ ), happiness (3.9 vs. $3.7, p<0.01)$, and obedience $(3.8$ vs. $3.7, p<0.05)$ compared with men. No gender differences were observed in the expectation of six filial domains.

\subsection{Correlations between Filial Piety Expectation, Receipt, and Socio-demographics}

Among the female cohort (Table 3), both filial piety expectation and filial piety receipt were negatively correlated with education $\left(\mathrm{r}^{\mathrm{E}}=-0.20 ; \mathrm{r}^{\mathrm{R}}=-0.11 ; \mathrm{p}<0.001\right)$ and positively correlated with number of children $\left(\mathrm{r}^{\mathrm{E}}=0.12 ; \mathrm{r}^{\mathrm{R}}=0.12 ; \mathrm{p}<0.001\right)$, preferred language as Cantonese $\left(\mathrm{r}^{\mathrm{E}}\right.$ $\left.=0.25 ; \mathrm{r}^{\mathrm{R}}=0.11 ; \mathrm{p}<0.001\right)$, and country of origin as China $\left(\mathrm{r}^{\mathrm{E}}=0.09 ; \mathrm{r}^{\mathrm{R}}=0.11 ; \mathrm{p}<0.001\right)$. Filial piety expectation was negatively correlated with overall health status $\left(\mathrm{r}^{\mathrm{E}}=-0.07, \mathrm{p}<0.01\right)$. Filial piety receipt was correlated with age $\left(r^{R}=0.06, p<0.05\right)$, income $\left(r^{R}=-0.09, p<0.001\right)$, living arrangement $\left(r^{R}=0.08, p<0.001\right)$, years in the $U S\left(r^{R}=-0.08, p<0.001\right)$, years in the community $\left(r^{R}=-0.06, p<0.01\right)$, overall health status $\left(r^{R}=0.07, p<0.01\right)$, quality of life $\left(r^{R}\right.$ $=0.21, \mathrm{p}<0.001)$, and health change over the last year $\left(\mathrm{r}^{\mathrm{R}}=0.07, \mathrm{p}<0.01\right)$. In addition, the expectation filial piety is significantly correlated with filial piety receipt $(r=0.38, p<0.001)$. 
Table 3. Correlations between filial piety and socio-demographic characteristics among women

\begin{tabular}{|c|c|c|c|c|c|c|c|c|c|c|c|c|c|c|c|}
\hline & Age & Edu & Income & MS & Living & Child & LP-CT & Yrs in US & Yrs in Com & Origin & OHS & QOL & $\mathrm{HC}$ & FP_E & FP_R \\
\hline Age & 1 & & & & & & & & & & & & & & \\
\hline Edu & $-0.18^{+}$ & 1 & & & & & & & & & & & & & \\
\hline Income & -0.04 & $0.11^{+}$ & 1 & & & & & & & & & & & & \\
\hline MS & $-0.44^{+}$ & $0.20^{+}$ & -0.03 & 1 & & & & & & & & & & & \\
\hline Living & $-0.32^{+}$ & -0.03 & $-0.10^{+}$ & $0.26^{+}$ & 1 & & & & & & & & & & \\
\hline Child & $0.32^{+}$ & $-0.40^{+}$ & $-0.07^{\#}$ & $-0.14^{+}$ & -0.03 & 1 & & & & & & & & & \\
\hline LP-CT & -0.02 & $-0.56^{+}$ & -0.03 & $-0.06^{+}$ & $0.06^{+}$ & $0.27^{+}$ & 1 & & & & & & & & \\
\hline Yrs U.S. & $0.38^{+}$ & $-0.09^{+}$ & $0.30^{+}$ & $-0.24^{+}$ & $-0.29^{+}$ & $0.13^{+}$ & $0.18^{+}$ & 1 & & & & & & & \\
\hline Yrs Com & $0.26^{+}$ & $-0.09^{+}$ & $0.19^{+}$ & $-0.16^{+}$ & $-0.20^{+}$ & $0.08^{+}$ & $0.20^{+}$ & $0.67^{+}$ & 1 & & & & & & \\
\hline Origin & 0.03 & $-0.08^{+}$ & $-0.20^{+}$ & $0.05^{*}$ & $0.06^{*}$ & $0.08^{+}$ & $0.06^{+}$ & $-0.23^{+}$ & $-0.15^{+}$ & 1 & & & & & \\
\hline OHS & $-0.08^{+}$ & $0.05^{*}$ & $0.10^{+}$ & 0.04 & -0.03 & 0 & -0.01 & 0.04 & $0.09^{+}$ & $0.07^{\#}$ & 1 & & & & \\
\hline QOL & 0.03 & $0.10^{+}$ & $0.06^{\#}$ & -0.02 & 0 & 0.04 & $0.12^{+}$ & 0.02 & -0.01 & $0.07^{\#}$ & $0.31^{+}$ & 1 & & & \\
\hline $\mathrm{HC}$ & $-0.13^{+}$ & 0.03 & $0.05^{*}$ & $0.07^{\#}$ & 0 & -0.03 & -0.03 & -0.02 & $0.06^{\#}$ & 0.01 & $0.33^{+}$ & $0.14^{+}$ & 1 & & \\
\hline FP_E & 0.003 & $-0.20^{+}$ & -0.02 & -0.04 & 0.04 & $0.12^{+}$ & $0.25^{+}$ & -0.02 & -0.01 & $0.09^{+}$ & $-0.07^{\#}$ & -0.03 & 0.006 & 1 & \\
\hline FP_R & $0.06^{*}$ & $-0.11^{+}$ & $-0.09^{+}$ & -0.01 & $0.08^{+}$ & $0.12^{+}$ & $0.11^{+}$ & $-0.08^{+}$ & $-0.06^{\#}$ & $0.11^{+}$ & $0.07^{\#}$ & $0.21^{+}$ & $0.07^{\#}$ & $0.38^{+}$ & 1 \\
\hline
\end{tabular}

${ }^{*} \mathrm{p}<0.05+\mathrm{p}<0.01 \quad \mathrm{H}<0.001 ; \mathrm{Edu}=$ Education; Child=Number of Children; MS=Marital Status; Living=Living Arrangement; Yrs in U.S. =Years in the US; Yrs in Com=Years in the Community; Origin=Country of Origin (Mainland as reference); OHS=Overall Health Status; $\mathrm{QOL}=$ Quality of Life; HC=Health Changes over the Last Year; LP-CT= Cantonese as language spoken; FP_E= Expectation of filial piety; FP_R= Receipt of filial piety.

Among the male cohort (Table 4), filial piety expectation was correlated with education $\left(\mathrm{r}^{\mathrm{E}}=\right.$ $-0.15, \mathrm{p}<0.001)$, living arrangement $\left(\mathrm{r}^{\mathrm{E}}=0.08, \mathrm{p}<0.01\right)$, number of children $\left(\mathrm{r}^{\mathrm{E}}=0.11\right.$, $\mathrm{p}<0.001)$, preferred language as Cantonese $\left(\mathrm{r}^{\mathrm{E}}=0.22, \mathrm{p}<0.001\right)$, and overall health status $\left(\mathrm{r}^{\mathrm{E}}=\right.$ $-0.08, \mathrm{p}<0.01)$. Filial piety receipt was correlated with income $\left(\mathrm{r}^{\mathrm{R}}=-0.06, \mathrm{p}<0.05\right)$, marital status $\left(\mathrm{r}^{\mathrm{R}}=0.07, \mathrm{p}<0.05\right)$, living arrangement $\left(\mathrm{r}^{\mathrm{R}}=0.09, \mathrm{p}<0.01\right)$, number of children $\left(\mathrm{r}^{\mathrm{R}}\right.$ $=0.08, \mathrm{p}<0.01)$, years in the $\mathrm{US}\left(\mathrm{r}^{\mathrm{R}}=-0.14, \mathrm{p}<0.001\right)$, years in the community $\left(\mathrm{r}^{\mathrm{R}}=-0.10\right.$, $p<0.001)$, being born in China $\left(r^{R}=0.11, p<0.001\right)$, overall health status $\left(r^{R}=0.10, p<0.001\right)$, and quality of life $\left(\mathrm{r}^{\mathrm{R}}=0.20, \mathrm{p}<0.001\right)$. Furthermore, filial piety expectation is significantly correlated with filial piety receipt $(\mathrm{r}=0.43, \mathrm{p}<0.001)$.In sum, for both genders, having more children was correlated with higher levels of filial piety expectation and receipt; poorer health status was correlated with higher expectation but lower receipt of filial piety. Moreover, married men were correlated with increased receipt of filial care while the correlation was not significant among women. Similarly, women with lower education received more filial piety while the trend was not observed among men. 
Table 4. Correlations between filial piety and socio-demographic characteristics among men

\begin{tabular}{|c|c|c|c|c|c|c|c|c|c|c|c|c|c|c|c|}
\hline & Age & Edu & Income & MS & Living & Child & LP-CT & Yrs in US & Yrs in Com & Origin & OHS & QOL & $\mathrm{HC}$ & FP_E & FP_R \\
\hline Age & 1 & & & & & & & & & & & & & & \\
\hline Edu & -0.03 & 1 & & & & & & & & & & & & & \\
\hline Income & $0.50^{*}$ & 0.04 & 1 & & & & & & & & & & & & \\
\hline MS & $-0.17^{+}$ & $0.10^{+}$ & -0.04 & 1 & & & & & & & & & & & \\
\hline Living & $-0.31^{+}$ & $-0.06^{*}$ & $-0.15^{+}$ & $0.19^{+}$ & 1 & & & & & & & & & & \\
\hline Child & $0.34^{+}$ & $-0.32^{+}$ & -0.01 & $-0.07^{*}$ & -0.05 & 1 & & & & & & & & & \\
\hline LP-CT & $-0.08^{\#}$ & $-0.56^{+}$ & $-0.08^{\#}$ & -0.03 & $0.08^{\#}$ & $0.24^{+}$ & 1 & & & & & & & & \\
\hline Yrs in U.S. & $0.32^{+}$ & $-0.06^{*}$ & $0.33^{+}$ & $-0.14^{+}$ & $-0.27^{+}$ & $0.13^{+}$ & $0.14^{+}$ & 1 & & & & & & & \\
\hline Yrs in Com & $0.22^{+}$ & $-0.08^{\#}$ & $0.23^{+}$ & $-0.08^{\#}$ & $-0.15^{+}$ & $0.08^{\#}$ & $0.15^{+}$ & $0.67^{+}$ & 1 & & & & & & \\
\hline Origin & $0.08^{\#}$ & $-0.08^{\#}$ & $-0.19^{+}$ & 0.02 & 0.02 & -0.01 & 0.05 & $-0.18^{+}$ & $-0.14^{+}$ & 1 & & & & & \\
\hline OHS & $-0.08^{\#}$ & 0.04 & $0.09^{\#}$ & 0.02 & 0.04 & -0.01 & -0.008 & -0.05 & 0.002 & 0.01 & 1 & & & & \\
\hline QOL & $0.11^{+}$ & $0.10^{+}$ & $0.06^{*}$ & 0.02 & -0.008 & 0.03 & $-0.13^{+}$ & -0.01 & -0.03 & -0.004 & $0.37^{+}$ & 1 & & & \\
\hline $\mathrm{HC}$ & $-0.08^{\#}$ & -0.01 & 0.03 & -0.05 & 0.01 & -0.04 & 0.02 & -0.05 & -0.01 & -0.02 & $0.35^{+}$ & $0.19^{+}$ & 1 & & \\
\hline FP_E & -0.01 & $-0.15^{+}$ & -0.02 & -0.001 & $0.08^{\#}$ & $0.11^{+}$ & $0.22^{+}$ & -0.04 & -0.02 & 0.05 & $-0.08^{\#}$ & -0.04 & -0.01 & 1 & \\
\hline FP_R & 0.03 & -0.04 & $-0.06^{*}$ & $0.07^{*}$ & $0.09^{\#}$ & $0.08^{\#}$ & 0.05 & $-0.14^{+}$ & $-0.10^{+}$ & $0.11^{+}$ & $0.10^{+}$ & $0.20^{+}$ & -0.004 & $0.43^{+}$ & 1 \\
\hline
\end{tabular}

${ }^{*} \mathrm{p}<0.05+\mathrm{p}<0.01 \# \mathrm{p}<0.001 ; \mathrm{Edu}=$ Education; Child=Number of Children; MS=Marital Status; Living=Living Arrangement; Yrs in U.S. =Years in the US; Yrs in Com=Years in the Community; Origin=Country of Origin (Mainland as reference); OHS=Overall Health Status; QOL $=$ Quality of Life; HC=Health Changes over the Last Year; LP-CT $=$ Cantonese as language spoken; FP_E= Expectation of filial piety; $F P \_R=$ Receipt of filial piety.

\subsection{Regression Model}

In the regression model (Table $5 \mathrm{a} \& 5 \mathrm{~b}$ ), filial piety expectation and receipt were the dependent variables. Independent variables were age, gender, education, income, marital status, number of children, years in the community, general health, quality of life, and health changes, etc. The difference was not significant between older women and men in the expectation of filial piety adjusted for the socio-demographics. However, women were 1.02 points higher than men in their perceived receipt of filial piety $(\mathrm{PE}=1.02, \mathrm{p}<0.001)$ adjusted for the socio-demographics. Lower education $(\mathrm{PE}=-0.18, \mathrm{p}<0.001)$ and having more children $(\mathrm{PE}=0.30, \mathrm{p}<0.001)$ indicate a higher level of filial piety expectation. In regards to filial piety receipt, age $(\mathrm{PE}=0.05, \mathrm{p}<0.001)$, income $(\mathrm{PE}=-0.21, \mathrm{p}<0.05)$, education $(\mathrm{PE}=-0.04, \mathrm{p}<0.05)$, number of children $(\mathrm{PE}=0.27, \mathrm{p}<0.001)$, living arrangement $(\mathrm{PE}=0.24, \mathrm{p}<0.001)$, and years in the U.S $(\mathrm{PE}=-0.04, \mathrm{p}<0.001)$ were all significant indicators. 
Table 5a. Gender difference in filial piety expectation among older adults

\begin{tabular}{llll}
\hline & & PE(SE) & \\
\hline & Model A & Model B & Model C \\
\hline Age & $-0.02(0.01)$ & $-0.03(0.02)$ & $-0.03(0.02)$ \\
Income & $-0.16(0.10)$ & $-0.14(0.10)$ & $-0.12(0.10)$ \\
Education & $-0.22(0.02)+$ & $-0.18(0.02)+$ & $-0.18(0.02)+$ \\
Married & & $-0.14(0.28)$ & $-0.12(0.28)$ \\
Children alive & & $0.31(0.08)+$ & $0.30(0.08)+$ \\
Living arrangement & & $0.12(0.06)^{*}$ & $0.11(0.06)$ \\
Years in the U.S & & & $-0.006(0.01)$ \\
Years in the community & & & $0.001(0.01)$ \\
Female & $\mathbf{0 . 4 0 ( 0 . 2 2 )}$ & $\mathbf{0 . 4 0 ( 0 . 2 4 )}$ & $\mathbf{0 . 3 8 ( 0 . 2 4 )}$ \\
\hline
\end{tabular}

Table 5 b. Gender difference in filial piety receipt among older adults

\begin{tabular}{llll}
\hline & Model A & PE(SE) & \\
\hline & $0.02(0.01)$ & Model B & Model C \\
\hline Age & $-0.42(0.07)+$ & $0.03(0.01)^{*}$ & $0.05(0.01)^{+}$ \\
Income & $-0.07(0.02)+$ & $-0.37(0.08)+$ & $-0.21(0.08)^{*}$ \\
Education & & $-0.03(0.02)$ & $-0.04(0.02)^{*}$ \\
Married & & $0.25(0.23)$ & $-0.22(0.23)$ \\
Children alive & & $0.26(0.07)+$ & $0.27(0.07)+$ \\
Living arrangement & & $0.29(0.05)+$ & $0.24(0.05)+$ \\
Years in the U.S & & & $-0.04(0.01)^{+}+$ \\
Years in the community & & & $-0.003(0.01)$ \\
Female & $\mathbf{1 . 0 3 ( 0 . 1 8 ) +}$ & $\mathbf{0 . 8 6 ( 0 . 1 9 ) +}$ & $\mathbf{1 . 0 2 ( 0 . 1 9 ) +}$ \\
\hline
\end{tabular}

$* \mathrm{p}<0.05, \# \mathrm{p}<0.01,+\mathrm{p}<0.001$.

\section{Discussion}

To our knowledge, this is the first population-based study that reports gender differences in the expectation and receipt of filial piety from U.S. Chinese older parents' perspectives. Older women perceived more filial piety receipt than older men while there is no gender difference in the expectation of filial piety. Older females reported a higher mean of overall filial piety receipt, including the receipt of respect, greetings, happiness, and obedience. Women with an older age and a lower educational level receive more filial piety while similar trends were not discovered among men. Being married correlated with higher levels of filial piety receipt 
among men but the correlation with marital status was not significant among women.

Our study indicates older women receive more filial piety than men while no significant gender difference was found in filial piety expectation. Our finding needs to be interpreted in the context of the Chinese cultural norms projected in gender difference in family obligations and relationships. An old Chinese saying “慈母严父” (amiable mother and disciplined father) suggests that children are culturally expected to establish a more affectionate connection with mothers and a more subordinate connection with fathers. Women's traditional role as the major caregivers within the family enables them to not only foster an intimacy with young children through daily nurturing, but also to maintain the closeness with adult children through shouldering some of the responsibilities in caring for grandchildren. Prior evidence suggested that grandparents taking care of grandchildren is an important inter-generational activity that embodies Chinese family-oriented values (Da, 2003). Specifically, grandmothers are often expected as the caregivers for the grandchildren in U.S Chinese community (Holroyd, 2005).

Filial behaviors are commonly endorsed among U.S Chinese except for financial support. Consistent with previous studies, respect is the mostly valued filial item and is placed with the highest level of expectation and receipt for both male and female older adults, while financial support is the least (Hamilton, 1996; Liu, $\mathrm{Ng}$, Loong, Gee, \& Weatherall, 2003). Specifically, women received more respect, greetings, happiness, and obedience than men. Our study suggests some filial behaviors may be valued more than others in the Chinese community. Moreover, our findings implied that male and female older adults may be more disparate in some filial behaviors, such as care and financial support, than other filial behaviors. Our findings shed some lights in delineating the evolving conceptualization of filial piety in the U.S Chinese community by gender: older men and women may not share as much in common in their perceptions toward obey, care, and financial support, as perceptions toward respect, happiness, and greetings.

It is worth of mentioning that married men are correlated with increased receipt of filial care while the correlation was not significant among women. One possible explanation is that women's proactive role of seeking filial care from children can lead to better filial care for their married male partners, who might be more reluctant in expressing filial needs due to the socially-anticipated role as the independent, decisive leader of the family (Lubben, 1989). A recent study showed that older men are more likely to get support from their wives and older women are more likely to get support from their children (Antonucci \& Akiyama, 1987; Chen, Simon, Chang, Zhen, \& Dong, 2014). Considering that the expectation of filial piety was not correlated with marital status for both female and male, our finding calls for additional attention to the vulnerability of the widowed male, who might not receive as much filial piety as they expected. In addition, our research highlights the essential role of females within the Chinese family as mothers and wives, the mediator between fathers and children in the practice of filial piety (Neufeld, Harrison, Hughes, Spitzer, \& Stewart, 2001).

Another intriguing finding in our study suggests women with an older age receive more filial piety from children while older age is not correlated with more filial piety receipt among men. 
Similarly, we found women with lower education receive more filial piety while the trend was not observed among men. We postulate that disadvantaged women are more likely to get attention and support from children because the vulnerability projected on women portraits more explicit and observable consequences (Chang, Simon, \& Dong, 2014). For instance, with the increase of age, the chances of being widowed are higher among women than men because women have a longer life expectancy and are usually younger than their husbands (Malatesta, Chambless, Pollack, \& Cantor, 1988; Burkhauser \& Smeeding, 1994). Moreover, a number of studies especially focused on women and identified that Chinese women in the U.S have higher risk of loneliness, stress, depressive symptoms, anxiety, suicidal ideation, and cognitive and physical impairment compared with men (Dong, Chen, Li, \& Simon, 2014; Dong, Chen, \& Simon, 2014; Dong, Chen, Wong, \& Simon, 2014; Simon, Chang, Zhang, Ruan, \& Dong, 2014; Zhang, Simon, \& Dong, 2014; Zhang, 2006; Chen \& Simon, 2015; Dong \& Zhang, 2015). Our findings noted the potential risk of overlooking the filial piety needs and the well-beings of Chinese older males in the Chinese community. Chinese older males are exposed to similar cultural and linguistic barriers and weakened social networks in the process of immigrating to U.S (Dion, \& Dion, 2001; Ngo-Metzger et al, 2003; Mui, Kang, Kang, \& Domanski, 2007; Dong, Zhang, \& Simon, 2014b). However, they were likely to receive less research attention from academic groups and less support from children because they did not appear as vulnerable as older females (Chang, \& Dong, 2014a; Chang, \& Dong, 2014b; Dong, Chang, \&Simon, 2014) Our conjecture can be supported by our finding that older males received less filial piety compared to their female counterparts while the expectations were similar. Further research is needed to explore the discrepancy between the expectation and the receipt of filial piety among Chinese older men.

For both genders, having more children was correlated with higher levels of filial piety expectation and receipt; poorer health status was correlated with higher expectation but lower receipt of filial piety. Our finding reflects that filial piety expectation and receipt are highly dependent on filial piety needs, resources, and capacities. Consistent with previous research (Guo \& Zhang, 1996), having more children indicates greater filial piety expectation and receipt because children are identified as an important source to secure adequate support in old age. Poorer health status probably may be associated with greater emotional and physical needs, possibly prompting higher expectations for filial care. However, it is possible that children are less capable to provide support and care for parents with poorer health due to the lack of professional knowledge, skills, and time commitment to perform the duty.

Limitations of this study warrant mention. First, our study is only representative of Chinese older adults in greater Chicago area, and it remains unclear whether our results can be generalized to other Chinese populations. Second, our study examined filial piety based on older adults' subjective assessment, which may be biased in estimating the actual receipt of filial piety. Third, our research asked older adults to provide an overall estimate of filial piety based on all their children and thus was not able to distinguish the performance of each child. In the future research, information needs to be collected regarding to children's demographics, for instance, gender, income, age, birth order, etc. Fourth, our study is cross-sectional, and thus we were not able to set up the temporal relationship between socio-demographic 
variables and filial piety measures. Future longitudinal research is necessary to understand the underlying mechanism why Chinese older females received more filial piety than older males while the expectations were on the similar level.

Our findings provided important implications to guide future research and elder care practices in U.S Chinese community. First, our study calls for future investigation of filial piety among male older adults, especially older men who are older, widowed, and with lower educational level, as they are of higher risk of not having filial piety needs satisfied. Future qualitative research is needed to provide a better understanding of the evolving conceptualization of filial piety and the gender differences in valuing filial behaviors.

Second, our study highlights that older females in Chinese families play important role in connecting their children and spouse to the practice of filial piety. Community educational programs should enhance inter-generational communications to foster the understanding between older parents and adult children, especially the interaction between fathers and their children. Chinese women's proactive role as the linkage between their husbands and children should be taken into account in developing family-based programs to improve generational interaction. Third, it is equally crucial for health practitioners to understand filial piety and its potential influences on older adults' health and well-beings. Health practitioners should show respect towards older patients' requests in asking for adult children's involvement in medical decisions and treatments. Moreover, family doctors should pay special attention to several vulnerable subgroups, including widowed male older adults, to inquiry about their filial needs and emotional well-beings. Fourth, policy-makers should facilitate the importance of filial piety through integrating generational solidarity and familial value into the design of social service and educational programs targeting at Chinese community. For instance, social service agencies can recognize adult children as home-makers of parents and subsidize children's time and efforts in taking care of their parents.

\section{Conclusion}

In sum, our study suggests women receive more filial piety from children although no gender difference was found in the expectation of filial piety. Older men who are older, widowed, and with lower educational levels are at higher risk of having unsatisfied expectations of filial piety. Interventions should be designed on the individual, family, and community levels, taking into consideration the female's essential role within Chinese families in regard to practicing filial piety.

\section{Acknowledgements}

We are grateful to Community Advisory Board members for their continued effort in this project. Particular thanks are extended to Bernie Wong, Vivian Xu, Yicklun Mo with Chinese American Service League (CASL), Dr. David Lee with Illinois College of Optometry, David Wu with Pui Tak Center, Dr. Hong Liu with Midwest Asian Health Association, Dr. Margaret Dolan with John H. Stroger Jr. Hospital, Mary Jane Welch with Rush University Medical Center, Florence Lei with CASL Pine Tree Council, Julia Wong with CASL Senior Housing, Dr. Jing Zhang with Asian Human Services, Marta Pereya with Coalition. 


\section{References}

Antonucci, T. C., \& Akiyama, H. (1987). An examination of sex differences in social support among older men and women. Sex roles, 17(11-12), 737-749. http://dx.doi.org/10.1007/BF00287685

Brakman, S.-V. (1994). Adult daughter caregivers. Hastings Center Report, 26-28. http://dx.doi.org/10.2307/3563495

Bureau., U. C. (2010). American Community Survey.: Washington: US Census Bureau.

Burkhauser, R. V., \& Smeeding, T. M. (1994). Social Security Reform: A Budget Neutral Approach to Reducing Older Women's Disproportional Risk of Poverty. Available at SSRN 1824592. http://dx.doi.org/10.2139/ssrn.1824592

Gallois, C., Giles, H., Ota, H., Pierson, H. D., Ng, S. H., Lim, T. S. \& Maher, J. (1996). Intergenerational communication across the Pacific Rim: An initial eight-nation study. In J. C. Lasry, J. G. Adairand \& J. G. Dion (Eds.), Latest Contributions to Cross-Culture Psychology (pp. 192-211) Lisse, Nethelands: Swets \& Zeitlinger.

Chao, S. Y., \& Roth, P. (2000). The experiences of Taiwanese women caring for parents-in-law. Journal of Advanced Nursing, 31(3), 631-638. http://dx.doi.org/10.1046/j.1365-2648.2000.01319.x

Chappell, N. L., \& Kusch, K. (2007). The gendered nature of filial piety-A study among Chinese Canadians. Journal of cross-cultural gerontology, 22(1), 29-45. http://dx.doi.org/10.1007/s10823-006-9011-5

Chang, E. S., Simon, M. A., \& Dong, X. Q. (2014). Using community-based participatory research to address Chinese older women's health needs: Towards sustainability. Journal of Women \& Aging (In Press).

Chang, E. S., \& Dong, X. (2014a). A Battery of Tests for Assessing Cognitive Function in US Chinese Older Adults-Findings From the PINE Study. The Journals of Gerontology Series A: Biological Sciences and Medical Sciences; 69(Suppl 2), S23-S30. http://dx.doi.org/10.1093/gerona/glu195

Chang, E. S., \& Dong, X. (2014b). Personality Traits among Community-Dwelling Chinese Older Adults in the Greater Chicago Area. AIMS Medical Science, 1(2), 73-86. http://dx.doi.org/10.3934/Medsci.2014.2.73

Chen, R., Simon, M. A., Chang, E.-S., Zhen, Y., \& Dong, X. (2014). The Perception of Social Support Among US Chinese Older Adults Findings From the PINE Study. Journal of aging and health, 26(7), 1137-1154. http://dx.doi.org/10.1177/0898264314529332

Chen, R., \& Simon, M. A. (2015). Gender Differences in Suicidal Ideation among U.S. Chinese Older Adults. Trauma, Aging, and Well-being, In Press.

Chow, E. N.-L. (1987). The development of feminist consciousness among Asian American women. Gender \& society, 1(3), 284-299. 
Da, W. W. (2003). Transnational grandparenting: Child care arrangements among migrants from the People's Republic of China to Australia. Journal of International Migration and Integration/Revue de l'integration et de la migration internationale, 4(1), 79-103. http://dx.doi.org/10.1007/s12134-003-1020-4

Dai, Y.-T., \& Dimond, M. F. (1998). Filial piety. A cross-cultural comparison and its implications for the well-being of older parents. Journal of Gerontological Nursing, 24(3), 13-18. http://dx.doi.org/10.3928/0098-9134-19980301-05

Dion, K. K., \& Dion, K. L. (2001). Gender and cultural adaptation in immigrant families. Journal of Social Issues, 57(3), 511-521. http://dx.doi.org/10.1111/0022-4537.00226

Dong, X., Chang, E.-S., Wong, E., \& Simon, M. (2011). Working with culture: lessons learned from a community-engaged project in a Chinese aging population. Aging Health, 7(4), 529-537. http://dx.doi.org/10.2217/ahe.11.43

Dong, X., Chang, E. S., \& Simon, M. A. (2014). Physical Function Assessment in a Community-Dwelling Population of US Chinese Older Adults. The Journals of Gerontology Series A: Biological Sciences and Medical Sciences, 69(Suppl 2), S31-S38. http://dx.doi.org/10.1093/gerona/glu205

Dong, X., Chen, R., Li, C., \& Simon, M. A. (2014). Understanding Depressive Symptoms Among Community-Dwelling Chinese Older Adults in the Greater Chicago Area. Journal of aging and health, 26(7), 1155-1171. http://dx.doi.org/10.1177/0898264314541697

Dong, X., Chen, R., \& Simon, M. A. (2014). Anxiety Among Community-Dwelling US Chinese Older Adults. The Journals of Gerontology Series A: Biological Sciences and Medical Sciences, 69(Suppl 2), S61-S67. http://dx.doi.org/10.1093/gerona/glu205

Dong, X., Chen, R., Wong, E., \& Simon, M. A. (2014). Suicidal ideation in an older US Chinese population. Journal of aging and health, 26(7), 1189-1208. http://dx.doi.org/10.1177/0898264314541696

Dong, X., Wong, E., \& Simon, M. A. (2014). Study design and implementation of the PINE study. Journal of aging and health, 0898264314526620. http://dx.doi.org/10.1177/0898264314526620

Dong, X., Zhang, M., \& Simon, M. A. (2014a). The expectation and perceived receipt of filial piety among Chinese older adults in the Greater Chicago area. Journal of aging and health, 26(7), 1225-1247. http://dx.doi.org/10.1177/0898264314541697

Dong, X., Zhang, M., \& Simon, M. A. (2014b). Self-mastery among Chinese Older Adults in the Greater Chicago Area. AIMS Medical Science, 1(1), 57-72. http://dx.doi.org/10.3934/medsci.2014.1.28

Dong X., \&Zhang, M. (2015). The Prevalence of Neurological Symptoms among Chinese Older Adults in the Greater Chicago Area. AIMS Medical Science, 2(1), 35-50. http://dx.doi.org/10.3934/medsci.2015.1.35 
Guo, Z., \& Zhang, K. (1996). Re-testing the role of the number of children in the family support for the elderly. Population Research, 2, 7-15.

Hamilton, B. (1996). Ethnicity and the family life cycle: The Chinese-American family. Family Therapy: The Journal of the California Graduate School of Family Psychology, 23(3).

Ho, D. Y.-f. (1994). Filial piety, authoritarian moralism, and cognitive conservatism in Chinese societies. Genetic, social, and general psychology monographs, 120(3), 347.

Ho, D. Y. (1996). Filial piety and its psychological consequences. In Bond, Michael Harris (Ed), The handbook of Chinese psychology (pp. 155-165). New York, NY, US: Oxford University Press.

Holroyd, E. (2005). Developing a cultural model of caregiving obligations for elderly Chinese wives. Western journal of nursing research, 27(4), 437-456. http://dx.doi.org/10.1177/0193945905274907

Kuo, B. C., \& Roysircar, G. (2004). Predictors of acculturation for Chinese adolescents in Canada: Age of arrival, length of stay, social class, and English reading ability. Journal of Multicultural Counseling and Development, 32(3), 143-154. http://dx.doi.org/10.1002/j.2161-1912.2004.tb00367.x

Li, N., Pang, L., Chen, G., Song, X., Zhang, J., \& Zheng, X. (2011). Risk factors for depression in older adults in Beijing. Canadian journal of psychiatry. Revue canadienne de psychiatrie, 56(8), 466-473.

Li, Y., \& Chi, I. (2011). Correlates of Physician Visits Among Older Adults in China The Effects of Family Support. Journal of aging and health, 23(6), 933-953. http://dx.doi.org/10.1177/0898264311401390

Liu, J. H., Ng, S. H., Loong, C., Gee, S., \& Weatherall, A. (2003). Cultural stereotypes and social representations of elders from Chinese and European perspectives. Journal of cross-cultural gerontology, 18(2), 149-168. http://dx.doi.org/10.1023/A:1025108618426

Lubben, J. E. (1989). Gender differences in the relationship of widowhood and psychological well-being among low income elderly. Women \& health, 14(3-4), 161-189. http://dx.doi.org/10.1300/J013v14n03_11

Malatesta, V. J., Chambless, D. L., Pollack, M., \& Cantor, A. (1988). Widowhood, sexuality and aging: a life span analysis. Journal of sex \& marital therapy, 14(1), 49-62. http://dx.doi.org/10.1080/00926238808403906

Mui, A. C., \& Shibusawa, T. (2008). Asian American elders in the twenty-first century: Key indicators of well-being: Columbia Univ Pr.

Mui, A. C., Kang, S. Y., Kang, D., \& Domanski, M. D. (2007). English language proficiency and health-related quality of life among Chinese and Korean immigrant elders. Health \& social work, 32(2), 119-127. http://dx.doi.org/10.1093/hsw/32.2.119 
Neufeld, A., Harrison, M. J., Hughes, K. D., Spitzer, D., \& Stewart, M. J. (2001). Participation of immigrant women family caregivers in qualitative research. Western Journal of Nursing Research, 23(6), 575-591. http://dx.doi.org/10.1177/01939450122045393

Ng, A. C. Y., Phillips, D. R., \& Lee, W. K.-m. (2002). Persistence and challenges to filial piety and informal support of older persons in a modern Chinese society: A case study in Tuen Mun, Hong Kong. Journal of Aging Studies, 16(2), 135-153. http://dx.doi.org/10.1016/S0890-4065(02)00040-3

Ng, R. M., \& Bhugra, D. (2008). Relationship between filial piety, meta-cognitive beliefs about rumination and response style theory in depressed Chinese patients. Asian journal of psychiatry, 1(2), 28-32. http://dx.doi.org/10.1016/j.ajp.2008.09.009

Ngo-Metzger, Q., Massagli, M. P., Clarridge, B. R., Manocchia, M., Davis, R. B., Iezzoni, L. I., \& Phillips, R. S. (2003). Linguistic and cultural barriers to care. Journal of general internal medicine, 18(1), 44-52. http://dx.doi.org/10.1046/j.1525-1497.2003.20205.x

Seelbach, W. C. (1977). Gender differences in expectations for filial responsibility. The Gerontologist, 17(5 Part 1), 421-425. http://dx.doi.org/10.1093/geront/17.5_Part_1.421

Short, S. E., Fengying, Z., Siyuan, X., \& Mingliang, Y. (2001). China's one-child policy and the care of children: An analysis of qualitative and quantitative data. Social Forces, 79(3), 913-943. http://dx.doi.org/10.1353/sof.2001.0025

Simon, M. A., Chang, E.-S., Rajan, K. B., Welch, M. J., \& Dong, X. (2014). Demographic Characteristics of US Chinese Older Adults in the Greater Chicago Area Assessing the Representativeness of the PINE Study. Journal of aging and health, 26(7), 1100-1115. http://dx.doi.org/10.1177/0898264314543472

Simon, M. A., Chang, E.-S., Zhang, M., Ruan, J., \& Dong, X. (2014). The Prevalence of Loneliness Among US Chinese Older Adults. Journal of aging and health, 26(7), 1172-1188. http://dx.doi.org/10.1177/0898264314533722

Smith, C. S., \& Hung, L.-C. (2012). The influence of Eastern philosophy on elder care by Chinese Americans attitudes toward long-term care. Journal of Transcultural Nursing, 23(1), 100-105. http://dx.doi.org/10.1177/1043659611423827

Tang, W., \& Parish, W. L. (2000). Chinese urban life under reform: The changing social contract: Cambridge University Press.

Yue, X., \& Ng, S. H. (1999). Filial obligations and expectations in China: Current views from young and old people in Beijing. Asian Journal of Social Psychology, 2(2), 215-226. http://dx.doi.org/10.1111/1467-839X.00035

Zhan, H. J., \& Montgomery, R. J. (2003). Gender And Elder Care In China The Influence of Filial Piety and Structural Constraints. Gender \& society, 17(2), 209-229. http://dx.doi.org/10.1177/0891243202250734

Zhang, Z. (2006). Gender differentials in cognitive impairment and decline of the oldest old 
in China. The Journals of Gerontology Series B: Psychological Sciences and Social Sciences, 61(2), S107-S115. http://dx.doi.org/10.1093/geronb/61.2.S107

Zhang, M., Simon, M. A., \& Dong, X. (2014). The Prevalence of Perceived Stress among U.S. Chinese Older Adults. AIMS Medical Science, 1(1), 40-56. http://dx.doi.org/10.3934/medsci.2014.1.40

\section{Copyright Disclaimer}

Copyright reserved by the author(s).

This article is an open-access article distributed under the terms and conditions of the Creative Commons Attribution license (http://creativecommons.org/licenses/by/3.0/). 